Roadmap for Narratively Describing Effects of Interventions in Systematic Reviews

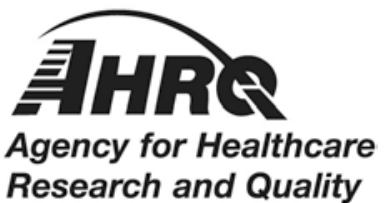




\section{Methods White Paper}

\section{Roadmap for Narratively Describing Effects of Interventions in Systematic Reviews}

Prepared for:

Agency for Healthcare Research and Quality

U.S. Department of Health and Human Services

5600 Fishers Lane

Rockville, MD 20857

www.ahrq.gov

\section{Contract No:}

290-2017-00003-C

290-2015-00013-I

290-2015-00001-I

290-2015-00008-I

290-2015-00007-I

290-2015-00011-I

290-2015-00010-I

290-2015-00009-I

290-2015-00002

1R03HS025840-01A1

Prepared by:

Scientific Resource Center

Portland, OR

Investigators:

Martha Gerrity, M.D, M.P.H., Ph.D.

Celia Fiordalisi, M.S.

Jennifer Pillay, M.Sc.

Timothy J. Wilt, M.D., M.P.H.

Elizabeth O'Connor, Ph.D.

Leila Kahwati, M.D., M.P.H.

Adrian V. Hernandez, M.D, Ph.D.

Carolyn M. Rutter, Ph.D.
Roger Chou, M.D.

Ethan M. Balk, M.D., M.P.H.

Dale W. Steele, M.D., M.S.

Ian J. Saldanha, M.B.B.S., M.P.H., Ph.D.

Orestis A. Panagiotou, M.D, Ph.D.

Stephanie Chang, M.D., M.P.H.

M. Hassan Murad, M.D., M.P.H.

AHRQ Publication No. 20(21)-EHC018

November 2020 


\section{Key Messages}

This document provides an approach to writing plain language and narrative statements for key systematic review results. It serves two goals: facilitate writing narrative statements and enhance consistency across reviews. The document identifies overlapping constructs that can be used in narrative statements based on the evidence user perspective and context.

\section{Key messages}

- Plain-language, narrative statements are helpful for most stakeholders, especially highlevel policymakers and the public.

- Five constructs (direction of effect, size of effect, clinical importance, statistical significance, and strength of evidence) should be considered when describing effects, recognizing that not all constructs will apply to all results or audiences.

- These constructs are not independent and greatly overlap.

- Based on stakeholders and context, writers can determine the relative importance of the constructs to address in narrative statements. Oversimplification of findings may risk misunderstanding for some audiences, but too much detail can be difficult to read or understand for others.

- Results should not be described solely based on their statistical significance.

- In evidence summaries and structured abstracts, Evidence-based Practice Centers can use summary statistics alongside narrative statements when necessary to convey the findings more clearly. When possible, avoid narrative statements in which summary statistics break up the flow of a sentence. 
This work was funded by the Agency for Healthcare Research and Quality through the following contracts: Mayo Clinic EPC (290-2015-00013-I), Scientific Resource Center (290-2017-00003C), University of Alberta EPC (290-2015-00001-I), University of Minnesota EPC (290-201500008-I), Kaiser Permanente Research Affiliates EPC (290-2015-00007-I), RTI-University of North Carolina EPC (290-2015-00011-I), Southern California/RAND EPC (290-2015-00010-I), Pacific Northwest EPC (290-2015-00009-I), Brown University EPC (290-2015-00002), and 1R03HS025840-01A1. The findings and conclusions in this document are those of the authors, who are responsible for its contents; the findings and conclusions do not necessarily represent the views of AHRQ. Therefore, no statement in this report should be construed as an official position of AHRQ or of the U.S. Department of Health and Human Services.

\section{None of the investigators have any affiliations or financial involvement that conflicts with the material presented in this report.}

The information in this report is intended to help healthcare decision makers—patients and clinicians, health system leaders, and policymakers, among others-make well-informed decisions and thereby improve the quality of healthcare services. This report is not intended to be a substitute for the application of clinical judgment. Anyone who makes decisions concerning the provision of clinical care should consider this report in the same way as any medical reference and in conjunction with all other pertinent information, i.e., in the context of available resources and circumstances presented by individual patients.

This report is made available to the public under the terms of a licensing agreement between the authors and the Agency for Healthcare Research and Quality. This report may be used and reprinted without permission except those copyrighted materials that are clearly noted in the report. Further reproduction of those copyrighted materials is prohibited without the express permission of copyright holders.

AHRQ or U.S. Department of Health and Human Services endorsement of any derivative products that may be developed from this report, such as clinical practice guidelines, other quality enhancement tools, or reimbursement or coverage policies, may not be stated or implied.

AHRQ appreciates appropriate acknowledgment and citation of its work. Suggested language for acknowledgment: This work was based on an evidence report, Roadmap for Narratively Describing Effects of Interventions in Systematic Reviews, by the Evidence-based Practice Center Program at the Agency for Healthcare Research and Quality (AHRQ).

Suggested citation: Gerrity M, Fiordalisi C, Pillay J, Wilt TJ, O’Connor E, Kahwati L, Hernandez AV, Rutter CM, Chou R, Balk EM, Steele DW, Saldanha IJ, Panagiotou OA, Chang S, Murad MH. Roadmap for Narratively Describing Effects of Interventions in Systematic Reviews. Methods White Paper. (Prepared by the Scientific Resource Center under Contract No. 290-2017-00003C.) AHRQ Publication No. 20(21)-EHC018. Rockville, MD: Agency for Healthcare Research and Quality. November 2020. Posted final reports are located on the Effective Health Care Program search page. DOI: https://doi.org/10.23970/AHRQEPCWHITEPAPERNARRATIVELY. 


\section{Preface}

The Agency for Healthcare Research and Quality (AHRQ), through its Evidence-based Practice Centers (EPCs), sponsors the development of evidence reports and technology assessments to assist public- and private-sector organizations in their efforts to improve the quality of healthcare in the United States. The reports and assessments provide organizations with comprehensive, science-based information on common, costly medical conditions and new healthcare technologies and strategies. The EPCs systematically review the relevant scientific literature on topics assigned to them by AHRQ and conduct additional analyses when appropriate prior to developing their reports and assessments.

To improve the scientific rigor of these evidence reports, AHRQ supports empiric research by the EPCs to help understand or improve complex methodologic issues in systematic reviews. These methods research projects are intended to contribute to the research base in and be used to improve the science of systematic reviews. They are not intended to be guidance to the EPC program, although may be considered by EPCs along with other scientific research when determining EPC program methods guidance.

AHRQ expects that the EPC evidence reports and technology assessments will inform individual health plans, providers, and purchasers as well as the healthcare system as a whole by providing important information to help improve healthcare quality. The reports undergo peer review prior to their release as a final report.

If you have comments on this Methods Research Project they may be sent by mail to the Task Order Officer named below at: Agency for Healthcare Research and Quality, 5600 Fishers Lane, Rockville, MD 20857, or by email to epc@ahrq.hhs.gov.

Gopal Khanna, M.B.A.

Director

Agency for Healthcare Research and Quality
Arlene Bierman, M.D., M.S.

Director

Center for Evidence and Practice Improvement

Agency for Healthcare Research and Quality

Stephanie Chang, M.D., M.P.H.

Director, Task Order Officer

Evidence-based Practice Center Program

Center for Evidence and Practice Improvement

Agency for Healthcare Research and Quality 


\title{
Roadmap for Narratively Describing Effects of Interventions in Systematic Reviews
}

\author{
Abstract \\ Accurately describing treatment effects using plain language and narrative statements is a \\ critical step in communicating research findings to end users. However, the process of \\ developing these narratives has not been historically guided by a specific framework. The \\ Agency for Healthcare Research and Quality Evidence-based Practice Center Program developed \\ guidance for narrative summaries of treatment effects that identifies five constructs. We \\ explicitly identify these constructs to facilitate developing narrative statements (1) size of effect, \\ (2) direction of effect, (3) clinical importance, (4) statistical significance, and (5) strength or \\ certainty of evidence. These constructs clearly overlap. It may not always be feasible to address \\ all five constructs. Based on context and intended audience, investigators can assess which \\ constructs will be most important to address in narrative statements.
}




\section{Contents}

Background ................................................................................................................................... 1

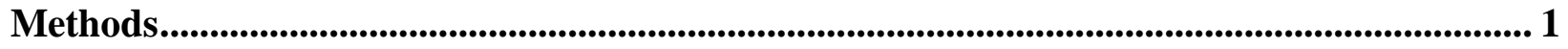

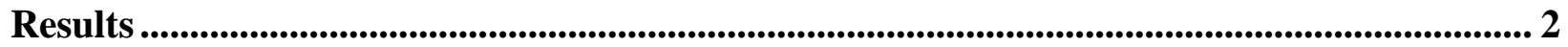

Constructs That Can Be Used To Describe Treatment Effects.................................................. 2

Overlap of Constructs ......................................................................................................... 4

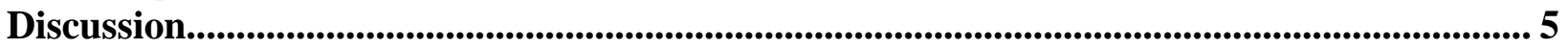

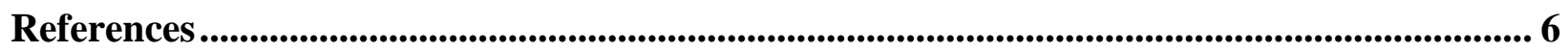

Abbreviations and Acronyms ................................................................................................................. 7

Tables

Table 1. Examples of narrative statements using the different constructs........................................ 4

Figures

Figure 1. Overlapping constructs that should be considered when describing effects 2

\section{Appendixes}

Appendix A. Suggested Phrases From Cochrane EPOC Guidance

Appendix B. Informative Statements To Communicate Results of Systematic Reviews From GRADE

Appendix C. Guide to Sections of EPC Reports Where Plain-Language Statements Are Most Useful 


\section{Background}

The Agency for Healthcare Research and Quality (AHRQ) Evidence-based Practice Center (EPC) program strives to ensure that end-users (guideline developers, clinicians, health system decision makers, and others) can find and interpret the information they need in EPC reports. When the audience for EPC reports includes policymakers and those interested in health system interventions, plain language descriptions of effects are particularly important. Narrative reporting of statistical findings offers unique challenges in terms of balancing readability and accuracy. The EPC program should ensure results are reported accurately, clearly, and succinctly so that they meet end-user needs.

\section{Methods}

The EPC program convened a workgroup (authors of this report) to review how intervention effects are described in EPC reports and recommend ways to improve readability. The workgroup reviewed guidance from the Cochrane Effective Practice and Organization of Care (EPOC) group published in $2018^{1}$ and the recently published Grading of Recommendations Assessment, Development and Evaluation (GRADE) 26 Guidance. $^{2}$

EPOC is a Cochrane review group that focuses mostly on health system interventions. EPOC has a particular interest in conveying findings to health systems and policy decision makers due to the subject matter of the topics the group addresses. The EPOC guidance suggests using simple, clear, consistent language to facilitate understanding of findings (Appendix A). It recommends only presenting results from the "most important" outcomes in abstract and summary documents and includes examples using their proposed standardized language. Their guidance also recommends not reporting summary statements for systematic review results as statistically significant or nonsignificant-a change from typical convention. However, the Cochrane EPOC guidance has not been universally adopted by other Cochrane groups.

The GRADE Working Group developed in 2004 an approach for rating the certainty in evidence that has been adapted by the EPC Program to rate strength of evidence in EPC reports. Recently, the GRADE Working Group has proposed an approach for making narrative statements. The workgroup surveyed producers and users of systematic reviews, convened a workshop of 80 methodologists, and developed a framework based on items that were acceptable to at least 60 percent of attendees. These two items were certainty of evidence and size of effect. The GRADE Working Group provided suggested narrative statements based on the size of effect within each level of certainty of evidence (Appendix B).

We started by pilot testing the use of the EPOC guidance on several completed EPC reviews. We then sought feedback from the AHRQ Learning Health System (LHS) Panel, comprising 11 decision makers from large health systems, to gauge their opinions on the use of plain language for key results in an Evidence Summary. Many of the 11 representatives had epidemiology or public health training and a greater understanding of research results than other decision makers in their organizations. Feedback from the LHS panel included: (1) avoid long compounded sentences that report several results within a single statement: (2) use the term "strength of evidence” instead of "certainty" when describing the evidence supporting a finding; and (3) use the term "probably" instead of "may" to describe findings supported by moderate strength of evidence. Members of the LHS panel varied in their preferences regarding the inclusion of quantitative results in plain language statements and whether $\mathrm{P}$ values should be included in the quantitative results. 


\section{Results}

We found the existing published guidance useful but had concerns that it may oversimplify findings or may be difficult to apply without known thresholds and assumptions. We also found that the existing guidance uses different underlying constructs to make these narrative statements but these constructs were not explicitly identified. Using EPOC and GRADE suggestions, we developed a framework (Figure 1) for key overlapping constructs that can be used to produce narrative statements describing treatment effects. The explicit identification of these constructs should not imply that they all should be used in every systematic review.

Figure 1. Overlapping constructs that should be considered when describing effects

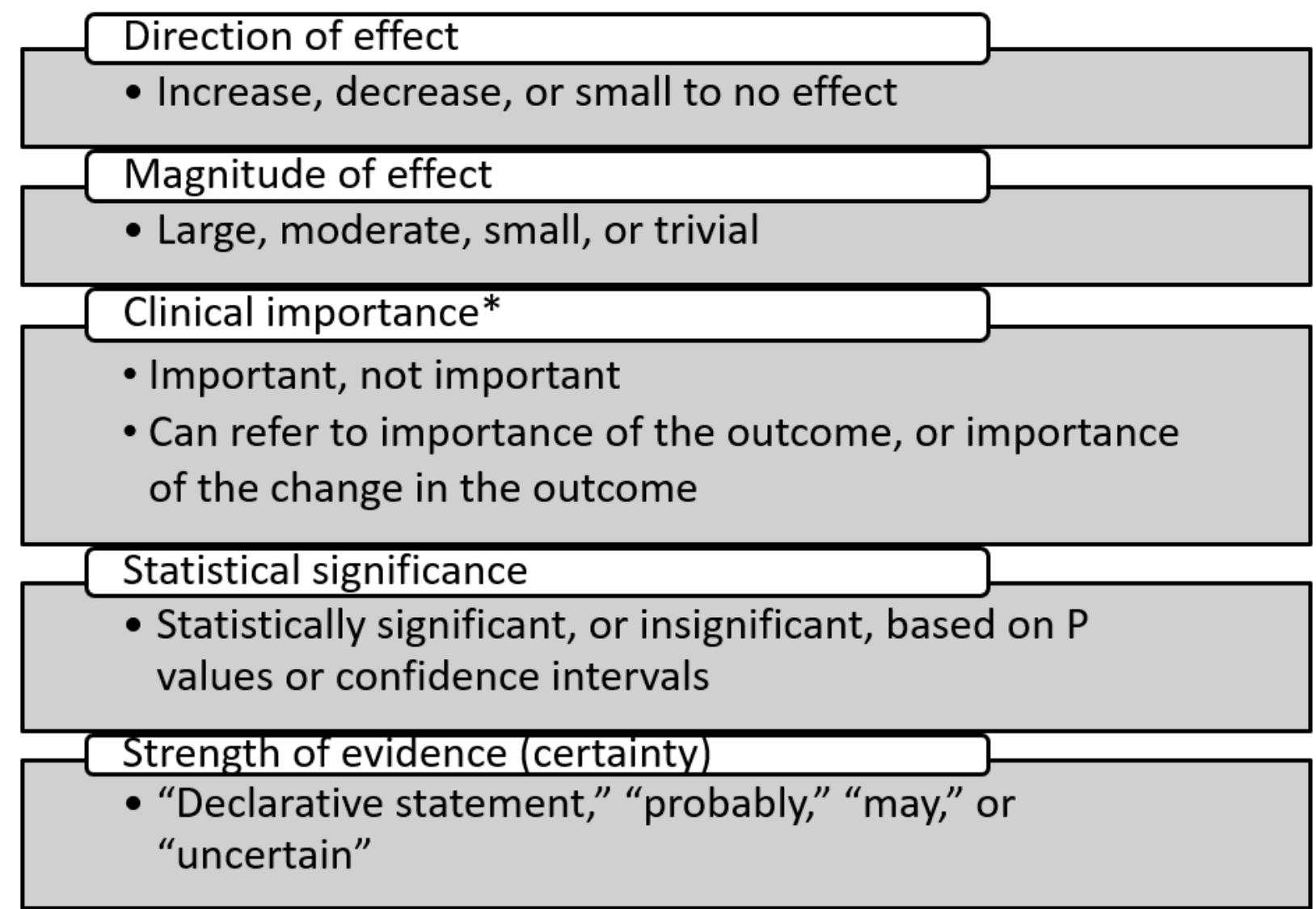

*The term "clinical importance" is appropriate in systematic reviews about clinical topics. However, other terms can be used in nonclinical settings, such as public health importance for example in systematic reviews about public health topics.

\section{Constructs That Can Be Used To Describe Treatment Effects}

Figure 1 depicts five constructs. For illustration, we proposed narrative statements based on results from two EPC systematic reviews ${ }^{3,4}$ using various combinations of the five constructs (Table 1). The examples include underlined text that refers to the constructs applied.

1. Direction: whether the intervention increases or decreases the risk of the outcome. The direction of effect could include "no or very small effect," however, this statement requires making a judgment that the effect is very small and not clinically important, thus overlapping with the concept of effect magnitude and clinical importance. The direction 
of effect is very important to convey in narrative statements particularly for end users with less training in statistics or epidemiology.

2. Magnitude: a quantitative estimate of the effect that is independent of the outcome's importance. For example, a relative risk of 5 indicates a very large magnitude of effect (strong association), even if the outcome was infrequent or not important (e.g., rare events or minor side effects for a drug with substantial health benefits). Narrative statements about the magnitude of effect can also describe absolute changes in binary outcomes (e.g., risk difference or number needed to treat, proportion of responders), continuous outcomes (e.g., a very large reduction in a laboratory parameter), or a standardized effect (e.g., reduction of more than 1 standard deviation of a scale), recognizing that for a given relative effect, absolute effects will vary across baseline risk.

3. Clinical importance: whether the magnitude of effect is meaningful or consequential to key stakeholders (patients, policymakers, providers, healthcare systems). Clinically important effects for a given outcome may vary across stakeholders and interventions, as well as across population subgroups (e.g., age, disease severity, comorbidities, preferences/values). Clinical importance is sometimes known (e.g., a minimal clinically important difference [MCID] of a scale ${ }^{5}$ defined as an effect noticeable to the individual), but in other instances may be more subjective-either statistically, arbitrarily, or consensus derived (e.g., a standard deviation or $25 \%$ relative improvement in symptom scale scores or a 5 percentage-point reduction in mortality may be assumed to be important). When information about clinical importance is unknown or poorly validated, investigators may choose to not use this construct when developing narrative statements. We also differentiate between the clinical importance of the change in the outcome, and the importance of the outcome itself (i.e., relative to other outcomes). These are two distinct concepts, although an assumption about the importance of the outcome is needed to make a judgment about the importance of the change. The term clinical importance is appropriate in systematic reviews about clinical topics. However, other terms can be used in nonclinical settings, such as public health importance for example in systematic reviews about public health topics.

4. Statistical significance: narrative statements can include the construct of statistical significance and refer to the results as statistically significant or not significant based on confidence intervals or $\mathrm{P}$ values. The interpretation of statistical significance will differ across systematic reviews based on the specific assumptions and inference frameworks.

5. Strength or certainty of evidence: a global judgment about the certainty in estimates across five domains: risk of bias, directness, precision, consistency, and likelihood of publication bias. The strength of evidence is rated in EPC reports as high, moderate, low, and insufficient. Narrative terms that may be used to correspond to these ratings, respectively, would be: declarative statements without adverbs or auxiliary verbs "the intervention reduces mortality," "probably reduces," "may reduce," and "it is uncertain whether the intervention reduces..." 
Table 1. Examples of narrative statements using the different constructs

\begin{tabular}{|c|c|c|}
\hline $\begin{array}{l}\text { Outcome, Underlying } \\
\text { Data and Assumptions }\end{array}$ & $\begin{array}{l}\text { Narrative Statement With Underlined } \\
\text { Text That Refers to the Constructs }\end{array}$ & $\begin{array}{l}\text { Constructs Addressed in the } \\
\text { Statement (in order as } \\
\text { underlined) }\end{array}$ \\
\hline $\begin{array}{l}\text { Resolution of COPD } \\
\text { exacerbations } \\
\text { OR } 2.03(95 \% \mathrm{Cl}, 1.47 \text { to } \\
2.80) \\
\text { Moderate SOE }\end{array}$ & $\begin{array}{l}\text { Antibiotics given for } 3 \text { to } 14 \text { days probably } \\
\text { increase the resolution of exacerbations in } \\
\text { patients with COPD. }\end{array}$ & $\begin{array}{l}\text { Strength of evidence } \\
\text { Direction of effect }\end{array}$ \\
\hline $\begin{array}{l}\text { 6-minute walking } \\
\text { distance } \\
\text { WMD: } 28.7 \text { meters ( } 95 \% \\
\mathrm{Cl}, 10.9 \text { to } 46.5) \\
\text { Moderate SOE } \\
\text { Improvement <30 meters } \\
\text { is considered not clinically } \\
\text { important }\end{array}$ & $\begin{array}{l}\text { Exercise programs after exacerbations of } \\
\text { COPD probably increase the 6-minute } \\
\text { walking distance by a margin that was } \\
\text { statistically significant but not clinically } \\
\text { important. }^{3}\end{array}$ & $\begin{array}{l}\text { Strength of evidence Direction } \\
\text { of effect } \\
\text { Statistical significance } \\
\text { Clinical importance }\end{array}$ \\
\hline $\begin{array}{l}\text { Anxiety symptoms } \\
\text { SMD: }-0.97(95 \% \mathrm{Cl},-1.31 \\
\text { to }-0.63) \\
\text { Low SOE } \\
\text { SMD > } 0.80 \text { suggests a } \\
\text { large effect }\end{array}$ & $\begin{array}{l}\text { In children with anxiety, fluvoxamine may } \\
\text { cause a large reduction in anxiety } \\
\text { symptoms. }{ }^{4} \\
\text { Alternatively: } \\
\text { In children with anxiety, fluvoxamine may } \\
\text { reduce anxiety symptoms. (avoid } \\
\text { commenting on the magnitude of effect } \\
\text { when the SOE is low) }\end{array}$ & $\begin{array}{l}\text { Strength of evidence } \\
\text { Magnitude of effect } \\
\text { Direction of effect }\end{array}$ \\
\hline $\begin{array}{l}\text { Serious adverse events } \\
\text { Rate Ratio: } 1.10(95 \% \mathrm{Cl} \text {, } \\
0.70 \text { to } 1.71) \\
\text { Low SOE }\end{array}$ & $\begin{array}{l}\text { In patients with acute exacerbation of } \\
\text { COPD, antibiotics may be associated with } \\
\text { little or no increase in serious adverse } \\
\text { events that was not statistically significant. }\end{array}$ & $\begin{array}{l}\text { Strength of evidence } \\
\text { Direction of effect } \\
\text { Statistical significance }\end{array}$ \\
\hline $\begin{array}{l}\text { Social function } \\
\text { SMD: } 0.35(95 \% \mathrm{Cl},-0.07 \\
\text { to } 0.76) \\
\text { Insufficient/very low SOE }\end{array}$ & $\begin{array}{l}\text { It is uncertain whether cognitive behavioral } \\
\text { therapy affects social function in children } \\
\text { with anxiety. }{ }^{4}\end{array}$ & Strength of evidence \\
\hline
\end{tabular}

Abbreviations: $\mathrm{CI}$ = confidence intervals; $\mathrm{COPD}$ = chronic obstructive pulmonary disease; $\mathrm{OR}$ = odds ratio; $\mathrm{RR}$ = risk ratio; $\mathrm{SMD}=$ standardized mean difference; $\mathrm{WMD}=$ weighted mean difference; $\mathrm{SOE}=$ strength of evidence

\section{Overlap of Constructs}

It is also clear that these constructs are interrelated and greatly overlap. For example, the size of an effect can affect the judgment about clinical importance. Clinical importance and size of effect may affect the determination of the direction of effect (e.g., differentiating between no effect or small effect). Statistical significance is related to precision of the estimate, which in turn is one of the domains that determine the strength of evidence construct. Judgments about the clinical importance and size constructs are needed to determine the precision and consistency domains of the certainty construct. Despite the overlap, it remains important to explicitly recognize these constructs when developing narrative statements. 


\section{Discussion}

Given that EPC reports have different levels of summary, we have outlined an approach for developing plain language summaries for different parts of evidence reports (Appendix C). The table points to various sections of a report where this roadmap for using plain language statements is applicable. Particularly, we suggest using plain-language statements in evidence summaries and structured abstracts. Summary statistics can be used alongside narrative statements when necessary to convey the findings more clearly. When possible, avoid narrative statements in which summary statistics break up the flow of a sentence. EPCs should refer to tables in the report for quantitative results and other details.

This document should serve as a roadmap for EPCs when describing the effects of interventions in a meaningful way for end-users. The framework can be applied to EPC reports of varying complexity. Describing results of complex results in plain language may be particularly important to certain evidence users. Narrative statements can be one of the tools that start the process of risk communication and a component of subsequent shared decision making. ${ }^{6}$ If scientific journals require manuscripts based on EPC reports to use different language than suggested in this framework, authors should strive to ensure that the variation in wording does not impact the interpretation of findings.

We recognize that describing the effects of interventions in plain language concisely and accurately can be particularly challenging. This document is not meant to be prescriptive or rigid. Rather, it aims to assist authors in writing high level summary statements and plain language statements that contribute to readable, accurate, and informative EPC reports. The roadmap will be undergoing trial use, and we will revisit and re-evaluate this document after receiving feedback from EPCs and end-users. We urge EPCs to continue to pay careful attention to and regularly evaluate their writing for clarity, readability, and usability. 


\section{References}

1. Cochrane Effective Practice and Organisation of Care (EPOC). Reporting the effects of an intervention in EPOC reviews.

https://epoc.cochrane.org/sites/epoc.cochrane.org/ files/public/uploads/Resources-forauthors2017/how to report the effects of an in tervention.pdf. In EPOC Resources for review authors

2. Santesso N, Glenton C, Dahm P, et al. GRADE guidelines 26: Informative statements to communicate the findings of systematic reviews of interventions. J Clin Epidemiol. 2019. doi: 10.1016/j.jclinepi.2019.10.014. PMID: 31711912

3. Dobler CC, Morrow AS, Farah MH, et al. Pharmacologic and Nonpharmacologic Therapies in Adult Patients With Exacerbation of COPD: A Systematic Review. Agency for Healthcare Research and Quality. 2019. doi: https://doi.org/10.23970/AHRQEPCCER221. PMID: 31657888.
4. Wang Z, Whiteside SP, Sim L, et al. Comparative effectiveness and safety of cognitive behavioral therapy and pharmacotherapy for childhood anxiety disorders: a systematic review and metaanalysis. JAMA Pediatr. 2017;171(11):1049-56. doi: 10.1001/jamapediatrics.2017.3036. PMID: 28859190

5. Johnston BC, Thorlund K, Schünemann HJ, et al. Improving the interpretation of quality of life evidence in meta-analyses: the application of minimal important difference units. Health Qual Life Outcomes. 2010;8(1):116. doi: 10.1186/1477-7525-8-116. PMID: 20937092

6. Hargraves I, Montori VM. Decision aids, empowerment, and shared decision making. BMJ. 2014 Sep 25;349:g5811. doi: 10.1136/bmj.g5811. PMID: 25255800. 


\section{Abbreviations and Acronyms}

AHRQ Agency for Healthcare Research and Quality

EPC

Evidence-based Practice Center

EPOC Effective Practice and Organization of Care

GRADE Grading of Recommendations Assessment, Development and Evaluation

LHS Learning Health System

MCID Minimal clinically important difference 


\section{Appendix A. Suggested Phrases From Cochrane EPOC Guidance}

Table A-1. Standardized statements for reporting effects

\begin{tabular}{|c|c|c|c|}
\hline $\begin{array}{l}\text { Certainty of } \\
\text { Evidence }\end{array}$ & Important Benefit/Harm & Less Important Benefit/Harm & $\begin{array}{l}\text { No Important } \\
\text { Benefit/Harm }\end{array}$ \\
\hline $\begin{array}{l}\text { High certainty } \\
\text { of evidence }\end{array}$ & $\begin{array}{l}\text { [Intervention] improves/reduces } \\
\text { [outcome] (high certainty } \\
\text { evidence) }\end{array}$ & $\begin{array}{l}\text { [Intervention] slightly } \\
\text { improves/reduces [outcome] } \\
\text { (high certainty evidence) }\end{array}$ & $\begin{array}{l}\text { [Intervention] makes little } \\
\text { or no difference to } \\
\text { [outcome] (high certainty } \\
\text { evidence) } \\
\text { Or } \\
\text { [Intervention] does not } \\
\text { have an important effect } \\
\text { on [outcome] } \\
\text { Or } \\
\text { [Intervention] has little or } \\
\text { no effect on [outcome] }\end{array}$ \\
\hline $\begin{array}{l}\text { Moderate } \\
\text { certainty of } \\
\text { evidence }\end{array}$ & $\begin{array}{l}\text { [Intervention] probably } \\
\text { improves/reduces [outcome] } \\
\text { (moderate certainty evidence) }\end{array}$ & $\begin{array}{l}\text { [Intervention] probably slightly } \\
\text { improves/reduces [outcome] } \\
\text { (moderate certainty evidence) } \\
\text { Or } \\
\text { [Intervention] probably leads to } \\
\text { slightly better/worse/less/more } \\
\text { [outcome] (moderate certainty } \\
\text { evidence) }\end{array}$ & $\begin{array}{l}\text { [Intervention] probably } \\
\text { makes little or no } \\
\text { difference to [outcome] } \\
\text { (moderate certainty } \\
\text { evidence) }\end{array}$ \\
\hline $\begin{array}{l}\text { Low certainty } \\
\text { of evidence }\end{array}$ & $\begin{array}{l}\text { [Intervention] may } \\
\text { improve/reduce [outcome] (low } \\
\text { certainty evidence) }\end{array}$ & $\begin{array}{l}\text { [Intervention] may slightly } \\
\text { improve/reduce [outcome] (low } \\
\text { certainty evidence) }\end{array}$ & $\begin{array}{l}\text { [Intervention] may make } \\
\text { little or no difference to } \\
\text { [outcome] (low certainty } \\
\text { evidence) }\end{array}$ \\
\hline
\end{tabular}

Table adapted from: Cochrane Effective Practice and Organisation of Care (EPOC). Reporting the effects of an intervention in EPOC reviews. https://epoc.cochrane.org/sites/epoc.cochrane.org/files/public/uploads/Resources-for-

authors2017/how_to_report_the_effects_of_an_intervention.pdf. Located in EPOC Resources for Review Authors, at https://epoc.cochrane.org/resources/epoc-resources-review-authors.

Table A-2. Standardized statements for reporting effects, continued

\begin{tabular}{|l|l|}
\hline \multicolumn{1}{|c|}{ Statement Category } & \multicolumn{1}{c|}{ Statement Options } \\
\hline Very low certainty of evidence & $\begin{array}{l}\text { We don't know if/It is uncertain whether [intervention] improves/reduces } \\
\text { [outcome] because the certainty of this evidence is very low. }\end{array}$ \\
\hline $\begin{array}{l}\text { The point estimate indicates } \\
\text { an important benefit or harm, } \\
\text { and the confidence interval } \\
\text { also includes an important } \\
\text { benefit/harm/no effect }\end{array}$ & $\begin{array}{l}\text { Option 1 } \\
\text { [Intervention] may lead to [better / worse outcome / little or no difference]. } \\
\text { However, the 95\% confidence inter indicates that [intervention] might make } \\
\text { little or no difference / might worsen / increase [outcome]. } \\
\text { Option 2 } \\
\text { [Intervention] may lead to [better outcome]. However, the range where the } \\
\text { actual effect may be (the "margin of } \\
\text { error") indicates that [intervention] may make little or no difference / might } \\
\text { worsen / increase [outcome]. } \\
\text { Option 3 } \\
\text { [Intervention] may lead to [better / worse outcome / little or no difference]. } \\
\text { However, the effects of [intervention] } \\
\text { vary and it is possible that [intervention] makes little or no difference / worsens } \\
\text { / increases [outcome]. }\end{array}$ \\
\hline No data or no studies & $\begin{array}{l}\text { OOtcome] was not measured/reported in the included studies. } \\
\text { No studies were found that reported [outcome]. }\end{array}$ \\
\hline
\end{tabular}

Table adapted from: Cochrane Effective Practice and Organisation of Care (EPOC). Reporting the effects of an intervention in EPOC reviews. https://epoc.cochrane.org/sites/epoc.cochrane.org/files/public/uploads/Resources-for- 
authors2017/how_to_report_the_effects_of_an_intervention.pdf. Located in EPOC Resources for Review Authors, at https://epoc.cochrane.org/resources/epoc-resources-review-authors. 


\section{Appendix B. Informative Statements To Communicate Results of Systematic Reviews From GRADE}

In all suggested statements, replace " $X$ " with intervention; replace "reduce/increase" with direction of effect; replace "outcome" with name of outcome; include "when compared with Y" when needed.

Table B-1. Suggested statements to convey high certainty of evidence

\begin{tabular}{|l|l|}
\hline Effect Size & \multicolumn{1}{|c|}{ High Certainty of Evidence } \\
\hline Large effect & X results in a large reduction/increase in outcome \\
\hline Moderate effect & X reduces/increases outcome \\
& X results in a reduction/increase in outcome \\
\hline Small important effect & X reduces/increases outcome slightly \\
& X results in a slight reduction/increase in outcome \\
\hline $\begin{array}{l}\text { Trivial, small unimportant effect or no } \\
\text { effect }\end{array}$ & X results in little to no difference in outcome \\
\hline
\end{tabular}

Table B-2. Suggested statements to convey moderate certainty of evidence

\begin{tabular}{|c|c|}
\hline Effect Size & Moderate Certainty of Evidence \\
\hline Large effect & $\begin{array}{l}X \text { likely results in a large reduction/increase in outcome } \\
X \text { probably results in a large reduction/increase in outcome }\end{array}$ \\
\hline Moderate effect & $\begin{array}{l}X \text { likely reduces/increases outcome } \\
X \text { probably reduces/increases outcome } \\
X \text { likely results in a reduction/increase in outcome } \\
X \text { probably results in a reduction/increase in outcome }\end{array}$ \\
\hline Small important effect & $\begin{array}{l}\text { X probably reduces/increases outcome slightly } \\
\text { X likely reduces/increases outcome slightly } \\
\text { X probably results in a slight reduction/increase in outcome } \\
\text { X likely results in a slight reduction/increase in outcome }\end{array}$ \\
\hline $\begin{array}{l}\text { Trivial, small unimportant effect or no } \\
\text { effect }\end{array}$ & $\begin{array}{l}X \text { likely results in little to no difference in outcome } \\
X \text { probably results in little to no difference in outcome } \\
\text { X likely does not reduce/increase outcome } \\
\text { X probably does not reduce/increase outcome }\end{array}$ \\
\hline
\end{tabular}


Table B-3. Suggested statements to convey low and very low certainty of evidence

\begin{tabular}{|c|c|}
\hline Effect Size & Low and Very Low Certainty of Evidence \\
\hline $\begin{array}{l}\text { Large effect } \\
\text { (Low certainty of evidence) }\end{array}$ & $\begin{array}{l}\text { X may result in a large reduction/increase in outcome } \\
\text { The evidence suggests } X \text { results in a large reduction/increase in } \\
\text { outcome }\end{array}$ \\
\hline $\begin{array}{l}\text { Moderate effect } \\
\text { (Low certainty of evidence) }\end{array}$ & $\begin{array}{l}X \text { may reduce/increase outcome } \\
\text { The evidence suggests } X \text { reduces/increases outcome } \\
X \text { may result in a reduction/increase in outcome } \\
\text { The evidence suggests } X \text { results in a reduction/increase in outcome }\end{array}$ \\
\hline $\begin{array}{l}\text { Small important effect } \\
\text { (Low certainty of evidence) }\end{array}$ & $\begin{array}{l}\text { X may reduce/increase outcome slightly } \\
\text { The evidence suggests } X \text { reduces/increases outcome slightly } \\
X \text { may result in a slight reduction/increase in outcome } \\
\text { The evidence suggests } X \text { results in a slight reduction/increase in } \\
\text { outcome }\end{array}$ \\
\hline $\begin{array}{l}\text { Trivial, small unimportant effect or no } \\
\text { effect } \\
\text { (Low certainty of evidence) }\end{array}$ & $\begin{array}{l}X \text { may result in little to no difference in outcome } \\
\text { The evidence suggests that } X \text { results in little to no difference in } \\
\text { outcome } \\
X \text { may not reduce/increase outcome } \\
\text { The evidence suggests that } X \text { does not reduce/increase outcome }\end{array}$ \\
\hline $\begin{array}{l}\text { Any effect } \\
\text { (Very low certainty of evidence) }\end{array}$ & $\begin{array}{l}\text { The evidence is very uncertain about the effect of } X \text { on outcome } \\
X \text { may reduce/increase/have little to no effect on outcome but the } \\
\text { evidence is very uncertain }\end{array}$ \\
\hline
\end{tabular}

Tables B-1, B-2, and B-3 adapted from Santesso N, Glenton C, Dahm P, et al. GRADE guidelines 26: Informative statements to communicate the findings of systematic reviews of interventions. J Clin Epidemiol. 2019. doi: 10.1016/j.jclinepi.2019.10.014. PMID: 31711912. 


\section{Appendix C. Guide to Sections of EPC Reports Where Plain-Language Statements Are Most Useful}

\begin{tabular}{|c|c|c|c|}
\hline Document & Section & Current Recommendation & Guidance Location \\
\hline \multirow[b]{2}{*}{$\begin{array}{l}\text { Evidence } \\
\text { Summary }\end{array}$} & $\begin{array}{l}\text { Main Points } \\
\text { (replaces } \\
\text { Key } \\
\text { Messages) }\end{array}$ & $\begin{array}{l}\text { - High-level narrative summary statements, } \\
\text { with little quantitative information* } \\
\text { Outcomes most closely related to } \\
\text { decisional dilemma }\end{array}$ & $\begin{array}{l}\text { Evidence summary content } \\
\text { guidance }\end{array}$ \\
\hline & Results & $\begin{array}{l}\text { Use table, if possible, in support of main } \\
\text { points } \\
\text { Does not require reporting all outcomes, } \\
\text { note that the full report covers more } \\
\text { outcomes }\end{array}$ & $\begin{array}{l}\text { Evidence summary content } \\
\text { guidance }\end{array}$ \\
\hline \multirow{3}{*}{ Full Report } & $\begin{array}{l}\text { Structured } \\
\text { Abstract }\end{array}$ & - Use narrative statements & $\begin{array}{l}\text { National Library of Medicine } \\
\text { guidance }\end{array}$ \\
\hline & $\begin{array}{l}\text { Key Points } \\
\text { by Key } \\
\text { Question }\end{array}$ & $\begin{array}{l}\text { - } \quad \text { Use narrative statements } \\
\text { - Only critical analytic findings. No detailed } \\
\text { study-specific results* } \\
\text { - } \quad \text { Presented as bullet points } \\
\text { Include direction and strength of evidence } \\
\text { assessment pertaining to the findings in } \\
\text { any bullet in this section }\end{array}$ & Full report content guidance \\
\hline & Results & $\begin{array}{l}\text { Provide number and design (RCT, } \\
\text { systematic review, etc.) of the included } \\
\text { studies and the number of participants } \\
\text { - Sentences can include numbers but not so } \\
\text { many that the sentence is unreadable } \\
\text { - Craft statements using framework as } \\
\text { necessary }\end{array}$ & $\begin{array}{l}\text { Describing effects framework; } \\
\text { full report content guidance }\end{array}$ \\
\hline
\end{tabular}

*Readers who need the details will have them in other sections of the report.

Abbreviations: RCT = randomized controlled trial. 